
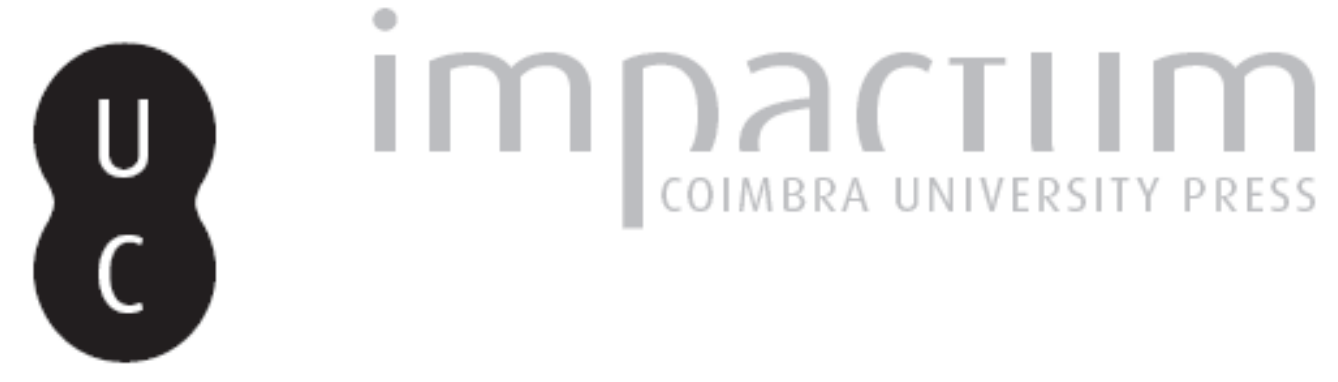

\title{
A Europa e Estados Unidos durante a administração Kennedy
}

Autor(es): Rocha, Miguel Estanqueiro

Publicado por: Centro de Informação Europe Direct de Aveiro; Centro de Estudos

Interdisciplinares do Século XX

URL

persistente:

URI:http://hdl.handle.net/10316.2/33988

DOI:

DOI:http://dx.doi.org/10.14195/1647-6336_11_17

Accessed : $\quad$ 26-Apr-2023 14:48:06

A navegação consulta e descarregamento dos títulos inseridos nas Bibliotecas Digitais UC Digitalis, UC Pombalina e UC Impactum, pressupõem a aceitação plena e sem reservas dos Termos e Condições de Uso destas Bibliotecas Digitais, disponíveis em https://digitalis.uc.pt/pt-pt/termos.

Conforme exposto nos referidos Termos e Condições de Uso, o descarregamento de títulos de acesso restrito requer uma licença válida de autorização devendo o utilizador aceder ao(s) documento(s) a partir de um endereço de IP da instituição detentora da supramencionada licença.

Ao utilizador é apenas permitido o descarregamento para uso pessoal, pelo que o emprego do(s) título(s) descarregado(s) para outro fim, designadamente comercial, carece de autorização do respetivo autor ou editor da obra.

Na medida em que todas as obras da UC Digitalis se encontram protegidas pelo Código do Direito de Autor e Direitos Conexos e demais legislação aplicável, toda a cópia, parcial ou total, deste documento, nos casos em que é legalmente admitida, deverá conter ou fazer-se acompanhar por este aviso.

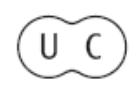


DEBATER

A EUROPA

jul-dez 2014

QUE EUROPA(S)?

CONTEXTOS E DESAFIOS 


\title{
EUROPA E OS ESTADOS UNIDOS DURANTE A ADMINISTRAÇÃO KENNEDY (1961-1963)
}

\author{
Miguel Estanqueiro Rocha \\ Professor Auxiliar Convidado na Universidade do Minho e na Universidade do Minho \\ Investigador Integrado CEIS20 \\ E-mail: miguelrocha25@hotmail.com
}

\section{Resumo}

Com o objectivo de repensar as relações transatlânticas, importa analisar o período da administração Kennedy (1961-1963), no auge da Guerra Fria. A presidência de John F. Kennedy implicou uma nova abordagem da política externa americana, com implicações nas relações entre os dois continentes. Neste âmbito, faz-se o estudo dos momentos mais marcantes das relações transatlânticas durante este período histórico: crise do muro de Berlim; crise dos mísseis de Cuba; divergências franco-americanas quanto à NATO e ao futuro do projecto europeu; apoio americano ao princípio de autodeterminação das colónias e as respectivas consequências nos relacionamentos com os aliados da NATO - França e Portugal.

Palavras-chave: Europa; descolonização; Kennedy; Guerra Fria; europeísmo

\begin{abstract}
In order to rethink the transatlantic relations, it is necessary to consider the period of Kennedy administration (1961-1963), at the height of the Cold War. The presidency of John F. Kennedy involved a new approach to American foreign policy, with implications in the relationships between the two continents. In this context, a study of the most important moments of the transatlantic relations during this historical period has been made: the Berlin Wall crisis; Cuban missile crisis; Franco-American differences towards NATO and the future of the European project; American support
\end{abstract}


for the principle of self-determination of the colonies and respective impact on relationships with NATO allies - France and Portugal.

Keywords: Europe; decolonization; Kennedy; Cold War; Europeanism

O assassinato trágico do Presidente John F. Kennedy, em Dallas, a 22 de Novembro de 1963, transformou o jovem presidente americano num dos ícones do século XX. O assassinato posterior do seu irmão, Robert F. Kennedy, em 1968, aquando da sua candidatura à Presidência, quando parecia, para muitos inevitável, a eleição de um segundo Kennedy para a Casa Branca, engrandeceu ainda mais a lenda que rodeia a dinastia mais famosa, mas também trágica da história política norte-americana, encontrando-se os dois irmãos sepultados no cemitério de Arlington.

\section{Kennedy: 50 anos depois}

No entanto, o desaparecimento prematuro de John Kennedy colocou um problema nunca cabalmente resolvido aos historiadores e analistas: como avaliar historicamente um mandato tão curto, mas tão prometedor, no auge da Guerra Fria e num período de profundas modificações na sociedade americana, com grandes repercussões ainda nos dias de hoje? Passado o período de grande emoção provocada pelo assassinato do Presidente, que levou a uma glorificação da sua Administração, verificou-se uma revisitação crítica da sua presidência e personalidade; no entanto, nos últimos anos, algum distanciamento histórico possibilita-nos uma análise histórica mais equilibrada da sua presidência: a de um presidente que soube preservar a paz, no auge da Guerra Fria e que, no plano interno, foi o precursor das transformações ocorridas na sociedade americana, embora tenha sido Lyndon Johnson, o seu sucessor, o responsável pela aprovação da legislação inovadora e progressista, nos Estados Unidos, durante a década de sessenta.

Sem o choque provocado pelo assassinato de Kennedy, aliado à astúcia e conhecimento que Johnson tinha do Congresso, provavelmente não teria sido aprovado pelo Congresso a Lei dos Direitos Civis, em 1964 (Themido, 1995: 73). No entanto, a capacidade para fazer aprovar no Congresso as suas propostas fez de Johnson um dos presidentes com melhor recorde legislativo da história presidencial norte-americana, com paralelo só com os tempos do New Deal de Franklin Roosevelt (Sabato, 2013: 277); contudo, o seu desconhecimento da política externa e a sua insegurança neste 
domínio contrastava com o interesse que John Kennedy sempre teve pelas relações internacionais (Sabato, 2013: 127). Só depois da sua vitória esmagadora nas eleições presidenciais de 1964, Lyndon Johnson conseguiu fazer aprovar no Congresso Americano as leis revolucionárias a nível da saúde, como foram o caso da aprovação do Medicare e do Medicaid, em 1965. Já Kennedy propusera a criação Medicare, em 1961, tendo sido o seu projecto rejeitado pelo Congresso.

No âmbito das relações internacionais, o grande legado histórico de Kennedy para a posteridade foi o de conservar a paz no auge da Guerra Fria; mesmo nos períodos mais críticos, em Berlim e em Cuba, o Presidente americano soube resistir à pressão dos militares para que se iniciasse um ataque à União Soviética, privilegiando soluções diplomáticas para os diferendos entre os Estados Unidos e a União Soviética. Transportando consigo as cicatrizes da experiência de combate na II Guerra Mundial, soube liderar o seu país por entre as águas turvas da Guerra Fria; após o fracasso da operação Baía dos Porcos, lidou com firmeza e flexibilidade em Berlim e Cuba, em 1961 e 1962. O fiasco do seu primeiro ano de presidência, a maturidade decorrente do exercício do cargo, trouxe-lhe uma desconfiança perspicaz sobre a sabedoria dos seus conselheiros militares da CIA e do Pentágono.

As relações transatlânticas constituíram uma das prioridades desta presidência marcante. Durante este período, o perigo de um conflito nuclear entre as duas superpotências, devido às crises de Berlim e de Cuba, ocuparam a agenda das relações entre os dois continentes. No entanto, a política externa da nova Administração não se limitou unicamente a estes assuntos, tendo a Casa Branca encorajado o aprofundamento da integração europeia, sinalizando, assim, o interesse com que este projecto era seguido em Washington. Nas relações com Paris, Londres e Bona residia outra preocupação do Presidente, determinado a preservar a Aliança Atlântica. A sua simpatia pelo processo de descolonização originou alguns momentos de tensão na NATO. A abertura à esquerda democrática italiana representou um momento de ruptura com a política da Administração Eisenhower.

\section{Keneedy e as relações internacionais}

A gestão de crise ficaria para sempre associada à política externa do $35^{\circ}$ Presidente dos Estados Unidos; eleito aos 43 anos, o primeiro e único católico a chegar à Casa Branca, tudo no novo dignatário despertava a imaginação mundial: a idade, a 
religião, o aspecto do novo casal presidencial, como se de estrelas de Hollywood se tratasse, após anos de "normalidade" com as presidência de Harry Truman e Dwight Eisenhower. Leitor ávido de história e dos seus grandes eventos (Talbot, 2007: 51), era na gestão da política externa que Kennedy almejava conquistar um lugar de relevo na história mundial. A sua presidência ficaria para sempre ligada aos momentos mais críticos da Guerra Fria - de Berlim a Cuba -, com o presidente americano a ter de lidar com a possibilidade de utilizar a arma nuclear e despoletar o terceiro conflito mundial. Seria aliás neste domínio que Kennedy também deixaria a sua marca na história, com as suas decisões a serem analisadas de um modo minucioso pelos historiadores.

A ascensão presidencial de Kennedy parecia indicar uma fase na política internacional, com uma nova geração no poder no auge da Guerra Fria, num momento histórico em que a Europa estava a ser governada por líderes históricos, mas já envelhecidos - De Gaulle, Adenauer, Macmillan. Kennedy simbolizava uma nova classe de políticos americanos, que combatera na II Guerra Mundial, que apoiara a política americana do pós-conflito, embora não a tivesse elaborado (Kissinger, 1994: 532), tornando-se numa referência de uma nova visão para um mundo aterrorizado, que vivia sob o espectro da guerra nuclear. O novel Presidente, com o seu estilo e acção política, tornar-se-ia uma inspiração também para uma nova geração de políticos europeus, desde Harold Wilson a Valéry Giscard D'Estaing e Willy Brandt. Mas Kennedy trazia consigo, para a Casa Branca, uma nova perspectiva da política mundial, dos desafios críticos com que Washington teria de lidar num mundo em mudança, um pensamento crítico relativo às opções da Administração republicana de Eisenhower, um novo olhar sobre os temas da agenda internacionais - entre os quais a descolonização, que contrastava com a indiferença anterior.

No âmbito da sua política externa, verificar-se-ia uma evolução interessante na acção política de John Kennedy: de apoiante convicto da luta ideológica com Moscovo, no auge da Guerra Fria, progrediu para uma nova fase, pugnando por uma melhoria nas relações entre as suas superpotências. O seu notável discurso na Universidade Americana, em 10 de Junho de 1963, é um comprovativo da preocupação do jovem Presidente em iniciar uma nova fase nas relações entre Washington e Moscovo, muito marcadas pela Guerra Fria (Dallek, 2013: 359-360): o Tratada Parcial de Interdição de Armas Nucleares, em 1963, e a sua proposta inovadora de uma expedição conjunta americano-soviética à lua, após ter proposto que os Estados Unidos colocassem um homem na lua até ao final da década de sessenta, são outros exemplos dessa vontade. $\mathrm{O}$ 
progresso no diálogo entre Washington e Moscovo nos últimos meses de presidência de Kennedy deixou para sempre uma dúvida histórica, que nunca terá resposta, sobre qual teria sido a evolução da Guerra Fria, caso Kennedy e Khrustchev tivessem permanecido no poder.

Apesar das críticas feitas à actuação de Kennedy no Vietname, ao seu legado de 16 mil conselheiros no Vietname do Sul, no momento do seu assassinato e que condicionou a actuação de Lyndon Johnson, uma análise cuidadosa permite-nos concluir que Kennedy não se teria comprometido no Vietname do mesmo que Johnson, como o National Security Memorandum 263, parece sugerir - neste memorando, Kennedy ordena a retirada de 1000 conselheiros do Vietname até ao final do ano (Talbot, 2007: 241). Embora Kennedy tenha aumentado o grau de envolvimento americano na região, a pesquisa histórica comprova como sempre resistiu à pressão da CIA e dos militares para um maior comprometimento americano, como recusou uma intervenção militar no Laos, em 1961. Seria com Johnson que os Estados Unidos chegariam a ter no Vietname 500 mil soldados, para evitar a queda do Vietname do Sul na órbita comunista. Para sempre ficou também sem resposta a incógnita de qual teria sido a posição americana neste conflito, caso não tivessem ocorrido as tragédias dos assassinatos de John Kennedy e Robert Kennedy, em 1963 e 1968 (Brodie, 1973: 144), nos períodos críticos do envolvimento americano no Sudoeste Asiático.

Uma mais-valia para a política externa americana residia na simpatia de Kennedy pelo movimento descolonizador. Herdeiro da tradição internacionalista e anticolonialista, corporizada por Woodrow Wilson e Franklin Roosevelt (Antunes, 1991: 49), John Kennedy defendia que os Estados Unidos não poderiam continuar a ser indiferentes à descolonização em África, unicamente devido ao receio de hostilizar as alianças com os países europeus (Antunes, 1991: 51). Vivia-se um período de mudança histórica com o fim dos impérios coloniais em África e Ásia, e os Estados Unidos não podiam continuar com a mesma política conservadora que caracterizara a actuação da diplomacia americana. Novos protagonistas chegavam à cena mundial, com novas propostas, e isso implicava uma nova abordagem de Washington.

Para Kennedy, a luta entre os dois modelos de sociedade deveria estender-se ao Terceiro Mundo (Antunes, 1991:169). Os Estados Unidos deveriam competir com Moscovo pela conquista da simpatia dos novos Estados independentes; aliás, em 1957, já se distinguira pelas críticas feitas ao Presidente Eisenhower sobre a Argélia, criticando a inacção do governo americano e defendendo a independência da Argélia, 
para irritação das autoridades francesas. Muito criticado na época pelo establishment americano, quer do partido republicano, quer do democrata, pela sua irresponsabilidade em abordar um assunto tão complexo, a evolução posterior dos acontecimentos demonstrou a sagacidade de Kennedy, pois a situação da Argélia exigia uma solução política, como mais tarde o Estado francês, sob a presidência de De Gaulle, o viria a reconhecer ao conceder a independência ao novo Estado. Mesmo criticado por sectores do establishment, Kennedy iniciaria uma aproximação aos novos países independentes e afirmaria a simpatia americana para com os povos colonizados, o que irritou os aliados próximos dos Estados Unidos, entre os quais, Salazar, em Portugal.

\section{Kennedy e a Europa}

Em relação à Europa, o novo chefe de Estado americano tinha de lidar com uma aliança em crise, ainda não refeita das feridas que a Crise do Suez causara nas relações transatlânticas. O desejo do presidente francês, De Gaulle, em dotar a França de poder nuclear, perante a oposição de Washington, e de afirmar a sua autonomia em relação ao que o General considerava ser o bloco anglo-saxónico, não deixava de ser encarado como um desafio aos Estados Unidos. A situação política em Itália encontrava-se num impasse. Berlim era uma questão sensível nas relações entre Washington e Moscovo, como o ano de 1961 o mostraria. O apoio tradicional às ditaduras ibéricas de Salazar e de Franco também condicionavam as opções de Kennedy, pois, no contexto da Guerra Fria, os Estados Unidos não poderiam dar-se ao luxo de hostilizar Lisboa e Madrid. Kennedy ambicionava ser o porta-voz da democracia, em confronto ideológico com o modelo comunista, mas também pretendia diminuir a tolerância com que os Estados Unidos encaravam as ditaduras de direita na Europa e na América Latina.

O discurso de tomada de posse de John Kennedy, a 20 de Janeiro de 1961, como presidente dos Estados Unidos, foi totalmente dedicado à política externa, aos desafios mundiais com os quais teria de lidar (Dallek, 2013: 106). Numa bela peça de oratória, considerada por muitos especialistas como um dos discursos de tomada de posse mais marcantes da história presidencial americana (Sabato, 2013: 75), Kennedy reafirmou o compromisso americano para com os valores de liberdade e da democracia; esse elo ligava os Estados Unidos aos seus aliados, nomeadamente aos europeus, mas os novos Estados recém-independentes, bem como os da América Latina, também foram saudados pelo novo chefe de Estado americano; o seu discurso inaugural tornou-se num sucesso, aclamado por todos aqueles que defendiam a manutenção das políticas 
tradicionais da Guerra Fria e também pelos que desejavam uma maior abertura de Washington para as realidades da década de sessenta (Talbot, 2007: 54). Deste modo, iniciava as suas novas funções no meio de grandes expectativas, que em muito ultrapassavam a margem mínima com que derrotara o candidato republicano, Richard Nixon, vice-presidente de Eisenhower.

John Kennedy tinha um interesse pelas relações externas que poucos presidentes americanos tiveram ao longo da história (Talbot, 2007: 71); tal como Richard Nixon, outro presidente conhecedor dos meandros da política internacional (Antunes, 1992: 28), John Kennedy queria deixar uma marca na história mundial e nada melhor do que a gestão da política externa para o garantir, quando a sua curta margem de vitória e a presença de um sector conservador no Congresso não permitiam um mandato caracterizado por grandes aprovações de programas legislativos inovadores (Sabato, 2013: 259). Toda a sua educação, a experiência de vida na Europa e a carreira política deveriam tornar-se numa mais-valia, permitindo ter uma compreensão dos fenómenos internacionais diferente da dos seus antecessores. Fiel às alianças tradicionais estabelecidas na Guerra Fria, Kennedy defendia uma aproximação ao Terceiro Mundo e fez disso uma prioridade da sua administração. Crítico da rigidez da administração Eisenhower, demasiado obcecada com a União Soviética e com a ameaça do comunismo (Mahoney, 1983: 19), a diplomacia americana teria de ser flexível face aos perigos e desafios com que os Estados Unidos lidavam no dealbar da década de sessenta, que exigiam uma nova atitude fora dos estereótipos da Guerra Fria.

Da América Latina à África e Ásia, o dinamismo de Kennedy fez-se desde logo notar: a sua proposta de uma Aliança para o Progresso representou uma ruptura com a prática dominante de Washington em associar-se às forças conservadoras da América Latina, para além de constituir uma resposta interessante à popularidade de que Castro e a revolução cubana desfrutavam nessa zona do globo. Apoiando-se em líderes reformistas, como o presidente da Venezuela, Rómulo Bettencourt, da Venezuela (Schlesinger, 2002: 267), Kennedy queria romper com a associação americana às forças mais conservadoras da América Latina. Com este programa e com o seu carisma, Kennedy pretendia contrabalançar o fascínio que Fidel Castro e a revolução tinham despertado na América Latina (Talbot, 2007: 79).

A criação do Peace Corps, em 1961, é outro exemplo ilustrativo do novo idealismo que guiava a política externa da nova administração: ao incentivar jovens americanos a trabalharem em países pobres, o Presidente americano ambicionava mudar 
a percepção que existia sobre o conservadorismo da diplomacia americana, aproximando-se mais das reivindicações dos países pobres. Criticada por sectores da vida política americana, viria a tornar-se num grande sucesso, com uma adesão surpreendente dos jovens americanos, que responderam ao repto do seu presidente com a sua disponibilidade para ter uma experiência de vida longe dos confortos da vida americana; mesmo alguns críticos viriam a reconhecer os seus méritos (Sabato, 2013: 81) por projectar uma imagem diferente dos Estados Unidos no cenário mundial. Com este projecto, Kennedy também pretendeu responder às acusações de Richard Nixon, durante as presidenciais de 1960, que definira o Partido Democrata como o partido da guerra (Dallek, 2013: 128), recordando o período da Guerra da Coreia.

Com o seu dinamismo, o Presidente americano pretendia revolucionar a política externa do seu país num período de confrontação ideológica entre dois modelos de sociedade antagónicos. Apesar do seu voluntarismo em relação a América Latina, da sua preocupação em abrir uma nova era nas relações com a América Latina, a nova política americana deparou-se com a oposição não só das forças conservadoras na América Latina, mas também da parte do establishment americano, que desconfiava das opções do seu novo presidente (Talbot, 2007: 81), acusado de contemporizar em demasia com a União Soviética e de ter permitido, com a sua inacção, a consolidação de um regime comunista a poucos quilómetros da costa da Florida.

A simpatia pelo movimento descolonizador seria uma novidade na política externa da Administração democrata. Celebrizado pelo seu discurso, em 1957, em que criticara a política americana na Argélia, a Casa Branca iniciou uma política de abertura aos novos países independentes. A rebelião em Angola, em 1961, permitiu a Kennedy demonstrar que as suas intenções deveriam ser levadas a sério, quando votou contra Portugal no Conselho de Segurança, em 15 de Março de 1961, ao lado da União Soviética. No início do conflito angolano, em 1961, a Administração procurou obter dos aliados europeus compreensão para a sua nova política africana - de oposição a Salazar -, esperando destes uma atitude cooperante e de intercessão junto do ditador português, convencendo-o a iniciar um processo de descentralização administrativa e política das colónias portuguesas. O objectivo americano consistia em preparar Angola e Moçambique para a sua emancipação, "libertando-os" do domínio português, evitando que estes territórios caíssem na órbita soviética. Todavia, o jovem Presidente americano confrontar-se-ia perante a oposição dos seus mais relevantes aliados, que se recusaram a hostilizar a política colonial portuguesa. Por seu turno, Portugal acusava os americanos 
de objectivos expansionistas, duvidando da sinceridade das suas promessas, caso alterasse a sua política colonial. O posicionamento dos três países europeus mais relevantes da NATO - França, RFA e Reino Unido - veio desmentir a tão divulgada tese do isolamento português (Rodrigues, 2002: 236).

No Médio Oriente, procurou estabelecer um diálogo construtivo com o líder egípcio Gamal Abdel Nasser (Bass, 2003: 247), e é considerado, por muitos especialistas, como o "founding father" da aliança dos Estados Unidos com Israel (Bass, 2003: 246), sendo a sua administração a primeira que forneceu equipamento militar ao Estado judaico (Mearsheimer e Walt, 2007:25), rompendo com o embargo existente desde as Administrações de Truman e de Eisenhower. Na Ásia, o Chefe de Estado americano procurou estabelecer uma boa relação com o primeiro-ministro da Índia, Jawaharlal Nehru, mas, apesar dos esforços de Kennedy, não se conseguiu criar um clima de confiança entre os líderes que possibilitasse uma nova era nas relações entre os dois países.

Nem a Europa fugiu ao desejo do Presidente em renovar a política externa do seu país. No entanto, a preservação da aliança transatlântica diante das ameaças da Guerra Fria só podia ser a prioridade do novo Presidente, com os anos críticos de 1961 e 1962 o comprovaram, em que o mundo parecia caminhar para o holocausto nuclear. A eleição de Kennedy despertara grandes expectativas na Europa, em muito devido ao facto de ser o primeiro católico presidente dos Estados Unidos. A viagem de Kennedy à Europa, em Maio e Junho de 1961, visou preservar a unidade transatlântica, essencial quando o líder americano tinha uma cimeira marcada com Krustchev em Viena; esta viagem tornou-se num êxito pessoal para Kennedy, saudado por multidões na Europa, com paragens em Paris, Viena e Londres.

Nas suas conversações com De Gaulle, em Paris, para além da divergência de posições face a temas prementes da agenda internacional - como o caso de Angola em que o presidente francês divergiu da posição crítica de Kennedy face a Portugal -, o Presidente americano conseguiu cativar De Gaulle (Schlesinger, 2002: 137). O presidente francês preconizava uma posição mais dura face a Moscovo na questão de Berlim, mesmo com o perigo de despoletar uma grave crise internacional, considerando que as exigências de Krustchev não passavam de mero bluff, com o objectivo de condicionar as posições ocidentais, porque a liderança soviética não desejava a eclosão de um conflito devido ao estatuto de Berlim (Dallek, 2003: 402-403). 
A subsequente cimeira de Viena com o líder soviético foi uma dura prova para o Presidente americano, convencido de que o seu charme seria suficiente para alcançar um acordo com a União Soviética, que limitasse os perigos de crises internacionais durante o seu mandato presidencial. As exigências feitas pelos soviéticos sobre Berlim, a ameaça de chegar a um acordo com a RDA (Dallek, 2013: 199) - condição essencial devido ao êxodo de cidadãos para Berlim ocidental -, levaram a um diálogo de surdos entre os representantes máximos das superpotências. $\mathrm{O}$ fracasso da cimeira tornou-se uma grande desilusão para Kennedy, que saiu decepcionado com esta experiência. $\mathrm{O}$ que parecia evidente para o Presidente americano era a sensação de não ser levado a sério pelo Kremlin. A própria decisão de Kennedy não invadir Cuba, aquando da malograda operação Baía dos Porcos, em 1961, convencera os soviéticos da fraqueza do Chefe de Estado americano, pois como Krustchev argumentara, era-lhe difícil levar a sério porque este era mais jovem que o seu próprio filho (Antunes, 1991: 247).

A consequência deste malogro seria o recrudescer das tensões entre Washington e Moscovo. Ao regressar a Washington, conferenciou com os líderes do Congresso e fez uma comunicação ao país, a 6 de Junho de 1961, para informar o público americano sobre os resultados da cimeira (Dallek, 2013: 201). Posteriormente, falou a 25 de Julho de 1961, reafirmando o compromisso americano para com a defesa de Berlim e os direitos ocidentais em Berlim Ocidental, anunciando um pedido ao Congresso de reforço das verbas as forças armadas americanas, e o reforço do exército americano de 875 mil homens para um milhão (Dallek, 2003: 423-424). Com este discurso, o Presidente procurava sossegar os seus aliados europeus, sobretudo os alemães (Dallek, 2003: 426), receosos de um possível entendimento entre Washington e Moscovo às suas custas, e também responder à ameaça soviética feita em Vienna de cortar os acessos a Berlim Ocidental. Durante o verão de 1961, pairou o perigo de uma confrontação militar entre os dois blocos; apesar de se recusar a intervir em Berlim Leste, sob domínio soviético, a Kennedy competia a responsabilidade de defender os direitos de Berlim Ocidental sob ameaça soviética, mesmo que conduzisse a um confronto militar.

A construção do Muro de Berlim, pelos soviéticos, em 13 de Agosto de 1961 seria o corolário deste momento perigoso de tensão. Confrontado com as reservas de Adenauer, Kennedy anunciou medidas simbólicas mas reveladoras da firmeza americana: enviou mais forças militares para Berlim Ocidental e incumbiu o vicepresidente, Lyndon Johnson, de aí se deslocar, juntamente com o General Lucius D. Clay - herói da ponte aérea que salvou Berlim do bloqueio soviético em 1948, com a 
função de aí receber os soldados (Dallek, 2003: 426-427). A presença do número dois da administração seria, do ponto de vista americano, mais uma garantia para os líderes alemães, ainda descontentes com a posição americana.

Durante os períodos mais tensos da Guerra Fria, Kennedy teve canais de comunicação com o líder soviético, procurando encontrar uma solução pacífica para os diferendos entre Washington e Moscovo. As cartas trocadas entre os dois líderes significaram que, não obstante as tensões, o bom senso ainda prevalecia. Simultaneamente, Kennedy procurou abrir canais de comunicação com o líder soviético, procurando encontrar uma solução pacífica para este diferendo. Esta troca de comunicações entre os dois líderes, à margem dos respectivos governos, representou um sinal de que, não obstante as tensões, o bom senso ainda prevalecia nos máximos dignatários das duas superpotências.

As relações com Paris não deixaram de constituir um dossier delicado na política europeia de Kennedy. Admirador de De Gaulle e do seu legado histórico, leitor ávido das memórias de guerras do líder francês, Kennedy procurou diminuir as tensões entre Washington e Paris - uma constante desde que o velho General regressara ao poder, estabelecendo uma parceria sólida com Paris; se a admiração mútua entre os dois líderes se tornou numa realidade indesmentível, as divergências bilaterais foram uma constante durante o mandato presidencial de Kennedy. A iniciativa francesa de dotar-se com armas nucleares não contava com a aprovação americana, que fez do combate à proliferação nuclear uma das suas prioridades. Já a decisão corajosa de De Gaulle em conceder a independência à Argélia foi acompanhada com interesse por Kennedy (Schlesinger, 2002: 207), simpatizante do movimento anticolonialista e que já se destacara, em 1957, pela defesa da independência da colónia francesa.

Após regressar ao poder em 1958, De Gaulle pôs logo em prática o seu plano: escreve, em Setembro de 1958, uma carta ao presidente Eisenhower e ao primeiroministro Macmillan, propondo uma revisão estrutural da NATO (Bozo, 2001: 17), sob a forma de um triunvirato, incluindo os EUA, o Reino Unido e a França; somente desta forma, pensava De Gaulle, a França teria na estrutura da NATO o poder correspondente à sua dimensão. Os americanos, como seria de esperar, não estavam de acordo com as ambições gaulistas. O presidente Eisenhower recusou tais pretensões e assistiríamos a um período negro nessas relações transatlânticas; note-se, contudo, que, embora discordasse das propostas francesas, o presidente Eisenhower era sensível às queixas francesas: recordava-se das humilhações infringidas pelo presidente Franklin D. 
Roosevelt ao General e à França, durante o segundo conflito mundial (Costigliola, 1992: 127), que chegara mesmo a propor a ocupação da França por tropas americanas, após a sua libertação, sendo esta governada por representantes americanos até à realização de eleições; seria, portanto, natural, que de Gaulle viesse a transportar consigo esses velhos ressentimentos.

Apesar, da reposta negativa de Eisenhower, De Gaulle não desiste dos seus intentos ${ }^{1}$; porém, tentando ainda consolidar o seu poder e a V República, entrega-se à resolução da sua maior prioridade política: cessar com a guerra da Argélia; só depois de resolvido o drama da Argélia é que De Gaulle irá dedicar-se ao seu grande objectivo: recuperar a grandeza da França no cenário mundial ${ }^{2}$. No entanto, essa política habilidosa do Presidente francês, por uma maior independência do seu País, não o impediu de demonstrar a sua solidariedade ao presidente Kennedy, e aos EUA, aquando da crise de Berlim (1961) e da crise dos mísseis de Cuba (1962) (Roussel, 2003: 264), nos momentos mais perigosos da confrontação entre os dois blocos, dando, entre os aliados, o apoio mais firme ao Presidente americano; não será acertado atribuir a política externa de De Gaulle unicamente a sentimentos anti-britânicos e antiamericanos; o presidente, para pôr em prática a sua política, teria que entrar inevitavelmente em rota de colisão com os seus parceiros ingleses e americanos.

Todavia, De Gaulle, manifestando o seu apoio aos americanos durante estas duas crises, acabaria por ver confirmada a sua desconfiança - que reforçara ainda mais a sua intuição de que a política francesa estava certa; o episódio dos mísseis de Cuba mostrara-lhe que os Estados Unidos, em crises graves, para a sua segurança, não consultariam os aliados sobre medidas a tomar, limitando-se simplesmente a informálos da decisão tomada. O presidente Kennedy, durante o processo de decisão, não consultou qualquer dos seus aliados, limitando-se depois a informar De Gaulle, Macmillan e Adenauer, da decisão tomada pela Administração americana, antes de a comunicar ao mundo.

\footnotetext{
${ }^{1}$ A política gaulista desenrolou-se em três períodos: de 1958-1962, as preocupações consistem em terminar com o conflito argelino e dotar a França de uma constituição presidencialista; o segundo, de 1962 a 1968, em que desenvolve as linhas mestres da sua política externa - reaproximação à Alemanha, distanciamento em relação ao Reino Unido e aos Estados Unidos -, e diálogo com a URSS - visando construir uma Europa do Atlântico aos Urais; na última fase, de 1968 a 1969, assiste-se a um recuo do projecto gaullista, provocado quer pela crise de Maio de 1968 quer pela invasão da Checoslováquia pelas tropas do Pacto de Varsóvia; tal recuo foi bem ilustrado com a calorosa recepção ao presidente Nixon, quando este visitou Paris, pondo-se um ponto final no período mais cinzento das relações franco-americanas (Zorgibe, 1990: 240).

2 Ao mesmo tempo, o General prosseguiu a política encetada pelos últimos governos da IV República, no que se refere ao armamento nuclear; para o Presidente, a França teria de dotar-se de armas nucleares: a explosão da primeira bomba atómica em 1960 e da bomba de hidrogénio em 1968 confirmaram os objectivos da política francesa: a França passava a pertencer ao grupo restrito de países com tal potencial bélico.
} 
As decisões posteriores tomadas no encontro Kennedy-Macmillan, em Dezembro de 1962, em que se resolveu a polémica dos mísseis Polaris, apenas confirmaram os velhos receios do General: a adesão britânica na CEE seria transpor para dentro da organização a presença americana; perante este cenário, determinado a garantir a independência do seu país face aos poderes anglo-saxónicos, a De Gaulle só restava a possibilidade de recusar a proposta anglo-americana. Quando Harold Macmillan aceitou a proposta de disponibilizar os mísseis Polaris para a força multilateral da NATO, logo o presidente francês entendeu tratar-se de mais uma manobra americana com o intuito de forçar a França a aceitar a mesma oferta, abdicando do seu arsenal atómico (Roussel, 2003: 272)

Com Adenauer, a relação passou por momentos de grande tensão. Ao líder histórico alemão coubera a responsabilidade de reerguer o seu país na comunidade internacional e de integrar a Alemanha no projecto europeu. A defesa da aliança com os Estados Unidos tornou-se uma prioridade para o estadista alemão, que ainda sonhava com a reunificação do seu país, tarefa essa impossível no auge da Guerra Fria. Após períodos de contacto privilegiado com a Casa Branca no passado, com Kennedy, o relacionamento seria diferente: para o presidente americano, Adenauer representava uma figura do passado (Freedman, 2002: 61) e os Estados Unidos deveriam prestar mais atenção à nova geração de líderes alemães, entre os quais se destacava Willy Brandt, por quem não ocultava a sua simpatia (Sorensen, 1965: 516); por seu turno, Adenauer não escondera a sua preferência por Richard Nixon nas eleições presidenciais americanas de 1960 (Sorensen, 1965: 488). A diferença de idades, as diferentes perspectivas sobre a realidade internacional e as posições divergentes sobre a Crise de Berlim criaram alguns momentos de tensão entre os dois países. Não obstante as tensões existentes entre as duas capitais, a popularidade do presidente americano na Alemanha atingia níveis elevados, como a sua visita à RFA, em 1963, o comprovaria. A firmeza do líder americano na crise do Muro de Berlim e na dos Mísseis de Cuba, apreciada por Adenauer (Sorensen, 1965: 503), contrastava com a desconfiança que o líder alemão tinha pelo jovem presidente, aquando da sua eleição.

Já no Reino Unido, as relações de Kennedy com Harold Macmillan não passaram pelas tensões que caracterizaram as relações com Paris e Bona. A empatia existente entre os dois líderes (Dumbrell, 2001: 49), a comunhão de opiniões sobre os temas dominantes da agenda internacional, apesar de algumas divergências, fez deste período um dos mais marcantes nas relações históricas entre Washington e Londres. Na 
Crise de Berlim, o primeiro-ministro britânico privilegiou sempre a solução política, mas procurando evitar a acusação de pacifismo e a percepção pública de divergências com os Estados Unidos (Dumbrell, 2001: 52-53). Já na crise dos Mísseis de Cuba, informado da decisão americana antes de ela ser comunicada ao mundo, o Reino Unido apoiou-a (Dumbrell, 2001: 54), dando provas de uma solidariedade transatlântica - tal como Paris e Bona o fizeram. A boa relação de amizade entre os dois dirigentes até permitiu ultrapassar um momento delicado nas relações bilaterais, que resultou da anulação americana da venda dos mísseis balísticos Skybolt ao Reino Unido, levando a um encontro Kennedy-Macmillan, em Dezembro de 1962, com a oferta americana dos mísseis Polaris, que também seriam oferecidos à França (Schlesinger, 2002: 300-301), por insistência do primeiro-ministro britânico (mas que não encontraria em de De Gaulle a mesma recepção entusiástica). Um factor interessante das relações entre Washington e Londres residiu na ligação de grande amizade entre o presidente americano e o embaixador britânico em Washington, David Ormsby Gore, e a grande confiança que o presidente americano depositava neste (Dumbrell, 2001: 50).

Seria em relação ao processo de integração europeia que Kennedy se destacaria, com uma proposta arrojada de uma nova parceria transatlântica: em 4 de Julho de 1962, ao saudar o projecto europeu, Kennedy propôs uma parceria entre os dois continentes, com uma Europa unida como parceira de Washington nos desafios globais. Numa Europa dividida pela Guerra Fria, e com a CEE constituída apenas por seis estados, o discurso do Presidente americano só podia ser entendido como um endosso aos ideais federalistas europeus de Jean Monnet e ao alargamento da CEE. Este discurso proferido em 1962, actual nos tempos em que vivemos - um período transitório das relações internacionais -, é uma oportunidade única, com vista a uma revisão das relações transatlânticas para o século XXI. De certo modo, precisamos de implementar, como sugere Timothy Garton Ash, a Declaração de Interdependência que fora proposta pelo presidente John F. Kennedy, em 1962 (Ash, 2005: 221); verdadeiramente, é mais o que une a Europa e os Estados Unidos que aquilo que os separa: partilhamos o mesmo sistema de valores civilizacionais e, sobretudo, os interesses estratégicos são convergentes. Embora o apoio de Washington ao projecto europeu fosse uma constante, independentemente das administrações no poder, Kennedy desejava estabelecer uma nova parceria entre os dois continentes, não só para enfrentar os perigos da Guerra Fria, mas também abraçar os desafios de amanhã. O seu discurso proferido a 4 de Julho de 1962 sinalizava a simpatia e o interesse com que Washington acompanhava o projecto 
europeu e o desafio que lançava aos seus aliados, para que edificassem uma nova comunidade política, de modo a renovar uma parceria transatlântica que não se limitasse unicamente a conter o perigo comunista.

Esta posição americana encontrou no presidente francês, De Gaulle, o seu maior adversário, pois para o presidente francês os Estados eram e deveriam a continuar a ser os únicos actores relevantes das relações internacionais. A edificação de uma ordem internacional em que as organizações internacionais tivessem um papel relevante deparava-se com a hostilidade da diplomacia gaulesa. Neste combate entre duas visões sobre o futuro da Europa, o Presidente francês, com o seu veto, em Janeiro de 1963, à adesão inglesa, levou a melhor sobre o projecto arrojado do Presidente americano (a decisão francesa de vetar a adesão do Reino Unido surpreendeu os Estados Unidos e o Reino Unido, admirados com a ousadia do gesto do presidente francês). Para De Gaulle, a participação britânica no projecto europeu significaria transpor para dentro da organização a influência americana, apesar dos Londres opor-se também à supranacionalidade (Roussel, 2003: 273) - ponto em comum com a visão gaullista sobre a Europa. Decisão solitária tomada pelo Eliseu, contestada pelos outros países membros da CEE, só seria modificada com a chegada de Georges Pompidou ao Eliseu, entrando o Reino Unido na Comunidade Europeia, apenas em 1973.

As surpresas preparadas por De Gaulle aos Estados Unidos não se limitaram unicamente ao veto à adesão britânica: a assinatura de um acordo de defesa com Adenauer, em Janeiro de 1963, representou mais um desafio de De Gaulle a Kennedy, pretendendo atrair a RFA para a sua orientação política de uma maior independência europeia face aos Estados Unidos. No entanto, apesar da assinatura alemã, todo o documento ficaria esvanecido do seu conteúdo durante o processo de ratificação no Bundestag: só foi aprovado após ter sido inserido um preâmbulo que se reafirmava o compromisso alemão com a aliança com os Estados Unidos (Roussel, 2003: 284-285); esta posição invulgar dos parlamentares alemães da CDU-CSU, FDP e SPD, enfureceu o Presidente francês (Roussel, 2003: 285), representando uma vitória da diplomacia americana e da sua capacidade de manobrar nos bastidores. Apesar de todas as suas tentativas de atrair os líderes alemães para os seus projectos, De Gaulle comprovava como seria difícil provocar uma alteração nas linhas programáticas da diplomacia alemã, não obstante a vontade de Adenauer em alinhar-se com Paris. A demissão de estadista alemão e a sua substituição na chancelaria pelo seu discípulo, Luding Ehrard, representou mais um revés para o Presidente francês, pois o novo Chefe de Governo 
alemão, para além do entusiasmo pela aliança com os Estados Unidos (Roussel, 2003: 291), não se distinguira na apologia do eixo franco-alemão, sobretudo quando pensado como um contrapoder à hegemonia dos Estados Unidos.

Importante na agenda europeia de Kennedy, a Itália, com uma situação internacional complicada, a presença de um partido comunista poderoso ameaçava tornar-se um problema complicado para Washington. A posição tradicional do Departamento de Estado, e seguida por Eisenhower, consistia no apoio à Democracia Cristã e na hostilidade à esquerda italiana (Schlesinger, 2002: 304), não obstante as divisões existentes nesta. Para Kennedy a política italiana passava por um momento de evolução: o poder da Democracia Cristã não permitia a estabilização do político italiano que estava a caminhar para um bloqueio, do qual só o Partido Comunista Italiano poderia beneficiar. Qual seria a melhor solução para desbloquear este impasse? A inclusão do Partido Socialista Italiano; a abertura do poder à esquerda moderada passou a ser vista como a melhor opção por muitos políticos da democracia-cristã, sendo também encorajada pela Casa Branca, que via nesta possibilidade um modelo para a França pós-De Gaulle e a Alemanha pós-Adenauer (Schlesinger, 2002: 304). Ao romper com a hostilidade face à esquerda, herdada de Eisenhower, fruto da radicalização de Nenni, líder histórico socialista, no final da década de quarenta, Kennedy optou por simbolizar a abertura aos partidos progressistas e de esquerda moderada que se opusessem aos respectivos partidos comunistas. A simpatia da Casa Branca era evidente para com alguns líderes progressistas, desde o alemão Willy Brandt, passando pelo britânico Hugh Gaitskell (Sorensen, 1965: 516).

Os períodos críticos da Guerra Fria são sempre os mais recordados e debatidos quando avaliamos a era da administração Kennedy. Mais de cinquenta anos passaram sobre estes eventos, a ameaça do holocausto nuclear pairou como uma ameaça e uma nuvem sombria atemorizava uma geração aterrorizada na era atómica. A guerra não eclodiu, mas estas tensões, que quase despoletaram um conflito nuclear, propiciam análises de grande interesse, na medida em que constituem ensinamentos para a gestão de futuras crises, obviamente sempre num contexto diferente.

\section{Bibliografia}

ANTUNES, José Freire (1991), Kennedy e Salazar: o leão e a raposa. Lisboa: Difusão Cultural. 
(1992), Nixon e Caetano, promesas e abandono. Lisboa: Difusão Cultural.

ARON, Raymond (1976), Penser la Guerre, Clausewitz, 2 vols. Paris: Gallimard.

(1983), Mémoires, 50 ans de réflexion politique. Paris: Julliard.

(2004), De Gaulle, Israel and the Jews, with and introduction by Michael Curtis.

New Brunswick (USA) and London (UK): Transaction Publishers.

ASH, Timothy Garton (2005), Free World, why a crisis of the West reveals the opportunity of our time. London: Penguin Books.

BASS, Warren (2003), Support Any Friend, Kennedy's Middle East and the making of the US-Israel alliance. Oxford: Oxford University Press.

BOZO, Frédéric (2001) De Gaulle, the United States and the Atlantic Alliance: two strategies for Europe. Oxford: Rowman \& Littlefield Publisher.

BRODIE, Bernard (1973), War \& Politics. New York: Macmillan Publishers.

BROGAN, Hugh (1996), Kennedy, Profiles in Power. Essex: Pearson education Limited.

CLARK, Thurston (2008), The Last Campaign, Robert F. Kennedy and 82 days that inspired America. New York: Holt Paperbacks.

COSTIGLIOLA, Frank (1992), France and the United States: the Cold Alliance since World War II. New York: Macmillan Publishing Company.

DALLEK, Robert (2003), John F. Kennedy, an Unfinished Life 1917-1963. London: Penguin Books.

(2013), Camelot's Court: Inside the Kennedy White House. New York: Harper Collins Publishers. 
DUMBRELL, John (2001), A special relationship, anglo-american relations in the Cold War and after. London: Macmillan Press LTD.

FERREL, Robert H. (1988), American Diplomacy: the Twenty Century. New YorkLondon: W.W. Norton \& Company.

FREEDMAN, Lawrence (2002), Kennedy's Wars, Berlin, Cuba, Laos and Vietnam. Oxford: Oxford University Press.

GAULLE, Charles de (1970), Memórias de Esperança, a Renovação: 1958-1962. Lisboa: Publicações Europa-América.

MAHONEY, Richard D. (1983), JFK: Ordeal in Africa. Oxford, New York: Oxford University Press.

MEARSHEIMER, John and Stephen M.Walt (2007), The Israel Lobby and the US Foreign Policy. New York: Farrar Straus Giroux.

KENNEDY, Edward M. (2009), A Memoir, Edward M. Kennedy, True Compass. London: Litle Brown.

KISSINGER, Henry (1994), A Diplomacia, trad. port. Lisboa: Gradiva, 1996. (1999), Years of Renewal. London: Phoenix Press. (2000), Years of Upheaval. London: Phoenix Press.

MONNET, Jean (1976), Mémoires. Paris: Fayard.

RODRIGUES, Luís Nuno (2002), Kennedy e Salazar: a crise de uma aliança, as relações entre Portugal e os Estados Unidos. Lisboa: Editorial Notícias.

ROUSSEL, Éric (2003), De Gaulle, 2 vols., Lisboa: Verbo. 
SABATO, Larry J. (2013), The Kennedy Half Century: the Presidency, Assassination and Lasting Legacy of John F. Kennedy. Bloomsbury: New York.

SCHLESINGER, Artur M. (1965), A Thousand Days: John F. Kennedy in the White House. London: Andre Deutsch. (2002), A Thousand Days: John F. Kennedy in the White House. New York: Black Dog \& Levanthal Publishers. (1978), Robert Kennedy and his Times. London: Andre Deutsch.

SIDEY, Hugh (1964), Kennedy Presidente. Barcelona: Editorial Juventud.

SHESOL, Jeff (1997), Mutual Contempt, Lyndon Jonhson, Robert Kennedy, and the Feud that Defined a Decade. New York, London: W.W Norton \& Company.

SORENSEN, Theodore C. (1965), Kennedy. Lisboa: Aster, s.d.

STEEL, Ronald (2000), In Love with the Night: the American Romance with Robert Kennedy. New York: Touchstone Publishers.

TALBOT, David (2008), A História Oculta dos Anos Kennedy. Lisboa: Casa das Letras.

THEMIDO, João Hall (1995), Dez Anos em Washington. Lisboa: Publicações Dom Quixote.

TOURNOUX, Raymond (1979), Le Feu et la Cendre: les années politiques du général de Gaulle, 1946-1970. Paris: Plon. 